\title{
PRESENCE OF ARTHROPOD PESTS ON EIGHT SPECIES OF BANKER PLANTS IN A GREENHOUSE
}

\section{PRESENCIA DE ARTROPODOS PLAGA EN OCHO ESPECIES DE PLANTAS BANCO EN UN INVERNADERO}

\author{
Pia Parolin ${ }^{1}$ Cécile Bresch, Gauthier Ruiz and Christine Poncet
}

\begin{abstract}
Despite precautions, the spontaneous invasion of undesired arthropod pests in greenhouses seems to be unavoidable. Secondary plants can be employed in biological control to enhance the proliferation of desired natural enemies of arthropod pests. However, these additional plants may also attract pests which in turn attack the crop plants. The present study is part of a long-term experiment to test eight species of banker plants (BPs) and their efficiency for biological protection against the spider mite Tetranychus urticae, employing the predatory mite Amblyseius californicus as natural enemy. Our goal was to find the best suited local plant species to be used as BPs, which enhances the reproduction and continuous release of the predators in a greenhouse. In the present paper, we document the spontaneous invasion of arthropods on eight species of BPs in a time span of three months, in a greenhouse in Southern France. The first arthropods appeared spontaneously on some of the plants after 4-8 weeks. After three months, there were 6 additional species of arthropods (whiteflies Trialeurodes vaporariorum, rose aphids Rhodobium porosum, gall midges Feltiella acarisuga, flower thrips Frankliniella occidentalis, parasitic wasps Encarsia sp. and predatory mites Phytoseiulus persimilis). Different species of plants attracted different species of arthropods. None of the pest arthropods reproduced on the available BPs in the experimental phase and thus did not represent a problem for the ornamental crop (rose plants). This shows that the mere presence of arthropods in a greenhouse might not affect the crop, as long as there is certain diversity of plant species. Although BPs may act as involuntary multipliers for pests, our study shows that, under the given conditions, this was not the case for the chosen BPs.

Key words: Banker plants, plant morphology, Integrated Pest Management, Amblyseius californicus, Tetranychus urticae, rose ornamental crops, Capsicum annuum, Crepis nicaeensis, Eleusine coracana, Lycopersicon lycopersicum, Rosa var. Sonia, Sonchus oleraceus, Viburnum tinus, Vitis riparia.
\end{abstract}

\section{Resumen}

En los cultivos de invernadero, a pesar de las precauciones, a veces es inevitable la instalación espontánea de especies no deseadas de plagas de artrópodos. Para el control biológico, se pueden emplear plantas secundarias que aumenten la proliferación de los enemigos naturales de dichos artrópodos plaga. Sin embargo, estas plantas adicionales también pueden atraer plagas que ataquen a los cultivos. El presente estudio tiene que ver con los datos producto del efecto secundario de un experimento a largo plazo que ponía a prueba ocho especies de plantas banco (PB) y su eficacia para la protección biológica contra el ácaro Tetranychus urticae, empleando al ácaro depredador Amblyseius californicus como enemigo natural. La intención era encontrar las mejores especies de plantas locales adecuadas para ser utilizadas como PB, que mejoren la reproducción y liberación continua de los depredadores en un invernadero. A pesar de todas las precauciones, después de un corto período hubo muchas especies exóticas en las PB en el invernadero. En el presente trabajo se documenta la instalación espontánea de artrópodos en ocho especies de BP en un plazo de tres meses, en un invernadero en el sur de Francia. Después de 4-8 semanas desde el inicio del experimento, los primeros artrópodos aparecieron espontáneamente en algunas de las plantas. Después de tres meses se encontraron 6 especies adicionales de artrópodos (moscas blancas Trialeurodes vaporariorum, áfidos rosa Rhodobium porosum, moscas hiel Feltiella acarisuga, trips Frankliniella occidentalis, avispas parásitas Encarsia sp. y ácaros depredadores Phytoseiulus persimilis). Diferentes especies de plantas atrajeron distintas especies de artrópodos, de acuerdo con las propiedades químicas específicas y los rasgos morfológicos, como hirsutismo foliar, superficies de cera, o la presencia de domatia, típico de algunas especies de plantas. Estas no se reprodujeron en las plantas disponibles en la fase experimental y por lo tanto no representaron un 
problema para los cultivos. Esto muestra que la presencia de los artrópodos en un invernadero no afecta seriamente el cultivo, siempre que hay una cierta diversidad de especies de plantas presentes. Es posible que las plantas banco actúen como multiplicadores involuntarios para las plagas, pero para las especies aquí elegidas, no hay evidencia de que esto suceda. Nuestro estudio muestra que las plantas banco elegido, en las condiciones dadas, no contribuyeron a una multiplicación de los artrópodos plagas.

Palabras clave Plantas banco, morfología de plantas, Manejo Integrado de Plagas, Amblyseius californicus, Tetranychus urticae, cultivos ornamentales de rosas, Capsicum annuum, Crepis nicaeensis, Eleusine coracana, Lycopersicon lycopersicum,Rosavar. Sonia, Sonchus oleraceus, Viburnum tinus, Vitis riparia.

\section{Introduction.}

Arthropod pests are almost omnipresent in traditional greenhouses in the Mediterranean region. Many efforts are undertaken to prevent thrips, aphids, whiteflies and many other pests from infesting crops or ornamentals which are raised in greenhouses. These arthropods are very efficient in dispersing to new sites and establishing rapidly-growing populations (Maelzer, 1977; Van Lenteren \& Hulspas-Jordaan, 1983; Johnston, 1993; Rhainds \& Shipp, 2004; Paynter \& Bellgard, 2011). In the end, the pests must be fought either by pesticides or by biological control, or sometimes both, or by other means.

The present study describes the infestation with various species of spontaneous pests on eight plant species which were tested as potential BPs for IPM in a rose crop system. BPs are non-crop plants that provide resources to sustain natural enemies of pests in the absence of their prey (Stacey, 1977; Frank, 2010; Huang et al., 2011; Parolin et al., 2012 a, b). They are introduced as rearing systems for biocontrol agents. Biological control agents such as predatory mites are released onto the BPs and as they reproduce and increase in numbers, they spread out into the rest of the greenhouse. These secondary plants (Parolin et al. 2012b) can be very useful in that they provide a means of continuous release of natural enemies into a crop system. However, they may potentially act as rearing sources for non-desired pests in the crop system. Therefore, it is important to test potential BPs not only with respect to the desired biocontrol agents but also with respect to their potential as rearing sources for pests. This was the purpose of the present paper.

An experiment was performed in a semi-open greenhouse in Southern France, in a setting which is typical for the local producers of ornamental plants in the region. The greenhouse was temperature-regulated by automatic opening and closing of the roof windows, thus giving access to flying organisms. One part of the experiment was to analyze growth and health of ornamental rose crops in combination with eight species of BPs in a long-term experiment (Parolin et al. 2013). In that study, we tested the efficiency of eight species of BPs to maintain a reproducing population of the predatory mite Amblyseius (Neoseiulus) californicus (McGregor) (Arachnidae, Acari, Phytoseiidae) to fight the pest mite Tetranychus urticae Koch (Acari, Tetranychidae) (Parolin et al. 2013). In the present study, we analyzed the presence and reproduction of spontaneous arthropod species on the same eight species of potential BPs. We made exact counts of the arthropod species and their progeny which efficiently established themselves on the plants after three months. This way, we provide insights into their proneness to be attacked by these pests and thus into their potential efficiency as BPs for greenhouses in the region. The chosen plant species are all typical of the region, either as local plants or as commonly grown crops, and represent different functional types (Parolin et al. 2012c). The employment of tested BPs for Integrated Pest Management (IPM) is highly recommended in order to avoid the frequent use of pesticides and the development of resistances (Zehnder et al., 2007).

\section{Material and methods.}

\section{Plants.}

Eight species of BPs with differing morphological characteristics were grown in a greenhouse: Capsicum annuum L. 'Poivron doux d'Espagne' (Solanaceae), Crepis nicaeensis Balb. (Asteraceae), Eleusine coracana (L.) Gaertn (Poaceae), Lycopersicon lycopersicum Kar. 'Saint-Pierre' (Solanaceae), Rosa sonia Meilland var. 'Sweet Promise' (Rosaceae), Sonchus oleraceus L. (Asteraceae), Viburnum tinus L. (Caprifoliaceae), Vitis riparia var. Gloire de Montpellier (Figure 1). In the following, and in the graphs, we refer to the species of BPs with the genus names only.

The choice of the species was based on their origin or traditional employment as crop plants in the Mediterranean area or on the knowledge about their efficient employment as BPs. We also looked for species with different physiognomic and morphological characteristics. Some species have hairy leaves and stems, others have waxy surfaces, and others bear domatia on the lower side of their leaves. Growth forms are distinct, ranging from a herb (Eleusine) with little structured physiognomy and few free standing leaves (e.g. Capsicum, Sonchus) to very 


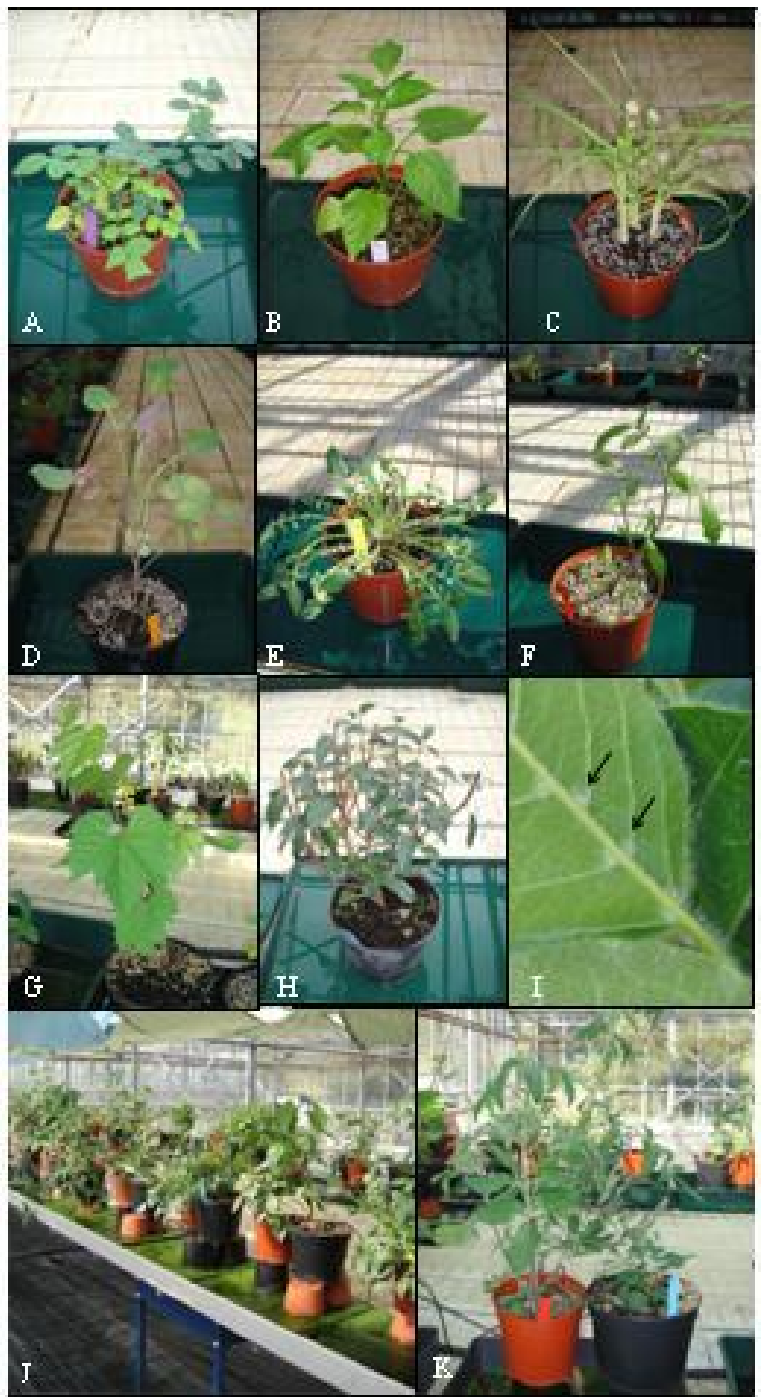

Figure 1. Species of banker plants employed in the experiment. (A) Rosa var. Sonia, (B) Capsicum annuum, (C) Eleusine coracana, (D) Sonchus oleraceus, (E) Crepis nicaeensis, (F) Lycopersicon lycopersicum, (G) Vitis riparia, (H) Viburnum tinus, (I) domatia (arrows) on lower leaf side of $V$. tinus formed by non-glandular trichomes, $(\mathrm{J})+(\mathrm{K})$ Experimental setting with one individual of each species placed in direct contact with a rose plant, trying to maximize the number of leaves in touch.

dense canopies with many leaves and many stem bifurcations (e.g. Viburnum, Parolin et al., 2011).

The plants were grown from seeds in a growing room and acclimatized in a greenhouse (Sonchus, Capsicum, Crepis, Eleusine, Lycopersicon) or produced in vitro (Rosa). Cuttings (20 cm length) of Vitis were ordered at the chamber of agriculture of Aude, France. One year-old plants of Viburnum (about $20 \mathrm{~cm}$ high) were ordered at "Les 3 chênes", a nursery in Orléans, France.
All plants were maintained in $1.3 \mathrm{~L}$ pots filled at $1 / 3$ with perlite and 2/3 with compost (horticultural and professional compost " Humomot » $\mathrm{pH}$ 6.5, conductivity $1.08 \mathrm{mS} / \mathrm{cm}$, field capacity 153\%) and were placed in the greenhouse $\left(23^{\circ} \mathrm{C}, \mathrm{RH}: 67 \%\right)$. They had a similar size (average $20-40 \mathrm{~cm}$ height) and age (approximately 5 months) at the beginning of the experiment. On 4 March 2010, all plants were placed in the greenhouse so they could adapt to the conditions before the experiment started with the inoculation of pests and predators. Plants and branches were cut before the experiment started, so that initial size within and between species was as equal as possible. Flowers were eliminated throughout the experiment because their pollen might influence the behavior of the pests and predators.

The experimental setting was optimized for the original experiment (Parolin et al. 2013) which aimed at testing eight plant species for their efficiency as BPs in association with roses. The experiment consisted of pairs of one rose plant and one BP (1 BP +1 associated crop rose) which were in close contact to improve connectivity, since the number of connections between plants has a significant impact on the dispersal of predators (Casey \& Parrella 2005).

Eight different species of BPs with differing morphological characteristics were employed in random combination with the rose plants (Figure 1). Rose plants were employed, both, as crop and as control BP in the experiment. Every species combination was repeated seven times, and three controls (no initial inoculation with pest and/or predatory mites).

In the present paper, we maintained the experimental setting to check for invasions of other arthropods on the same plant individuals as employed for the fore-mentioned experiment. On 11 March 2010, each BP was infested with 10 individuals of $T$. urticae. On 25 March 2010, the same plants were inoculated with 10 predatory mites (A. californicus) per BP. This was the start of the experimental phase to test the eight plants, each one of which was placed in contact with a rose plant, the focal ornamental crop. The experiment ended after three months, on 17 June 2010 as thereafter the temperature in the non-regulated greenhouse was too elevated.

Ten individuals of each species, each one paired with a rose plant, were placed on a table in the greenhouse with a distance of $30 \mathrm{~cm}$ between the pots, taking care that there was no touching point between the plants. The pots were placed in trays filled with water to inhibit migration of mites from one plant pair to the other.

\section{Arthropods.}

Two species of mites were transferred to both BPs and roses plants for the main experiment (Parolin et al. 2013): the two-spotted spider mites T. urticae (Acari, Tetranychidae), and the generalist predatory 
mite A. californicus (Arachnidae, Acari, Phytoseiidae) which feeds on various arthropods and pollen. $T$. urticae was reared on rose and bean plants in the laboratory before the experiment started. The commercial strain Spical ${ }^{\circledR}$ of A. californicus was ordered from Koppert and transferred to plants within 2 days upon arrival. Pollen from Pinus halepensis P. Mill., collected from trees outside the greenhouse, was added to all plants at regular intervals in order that food was not limiting for the predators on all the plants.

The other arthropod species, which appeared spontaneously on the plants and were the study objects for the present paper, were determined to species level by local experts from INRA.

Flies of the genera Sciaridae and Ephydridae (Diptera) were recorded on the borders of the greenhouse and determined by the specialist for the insect family, Prof. Stefan Kühn (Julius-KühneInstitute, Berlin). However, they were not seen on any of the BPs: thus, they were not considered further in the present paper.

Assessment of the presence of arthropods.

At the end of the experiment, after three months, all arthropods (adult, young, eggs) present on all BPs and associated roses were counted using a lens with a magnification of 10x. Additionally, we counted hidden arthropods and eggs (e.g. in domatia) after destructive sampling. Leaves were detached and taken to the lab for detailed counting of all present arthropods using lenses and a stereo microscope.

Infestation of $T$. urticae, A. californicus, aphids and whiteflies exceeded the threshold if more than 5 individuals were found on plants (Casey et al., 2007). For the other arthropods (gall midges, thrips, Encarsia, $P$. persimilis), we used a threshold of 1-3 individuals per plant.

Climate.

The plants were exposed in the greenhouse from 4 March to 17 June 2010 at INRA Sophia Antipolis, Southeastern France. The climate in the greenhouse was only little regulated i.e. no heating or cooling other than through open windows, which corresponds to the practice of most local producers in Southern France. Temperature and humidity were measured at hourly intervals with an Aria hygrometry sonde (ref. SDE-HYGRO-4) and Aria temperature sonde (ref. SDTEOA45, SDTS 0/60) and recorded at hourly intervals by Aria Soft. The temperature ranged from a minimum of $3.6^{\circ} \mathrm{C}$ during nights in spring to a maximum of $35.1^{\circ} \mathrm{C}$ during daytime in June, with an average of $18.8^{\circ} \mathrm{C}$ (sd 6.3) for the whole study period. Relative air humidity, in the same period, ranged from 20 to $91 \%$, with an average of $65.5 \%$ (sd 19.6).

\section{Results.}

The first appearance of arthropods on plants varied between 4-8 weeks from the start of the experiment.
After three months in the greenhouse there were a total of six additional species of arthropods present on plants, besides the pest ( $T$. urticae) and the predatory (A. californicus) mites, released on plants 12-15 weeks earlier. These included greenhouse whiteflies Trialeurodes vaporariorum Westwood (Homoptera: Aleyrodidae), rose aphids Rhodobium porosum L. (Hemiptera: Aphididae), gall midges Feltiella acarisuga Vallot (Arthropoda, Insecta), western flower thrips Frankliniella occidentalis Pergande (Thysanoptera: Thripidae), parasitic wasps Encarsia sp. (Hymenoptera: Aphelinidae), and predatory mites Phytoseiulus persimilis Athias-Henriot (Phytoseiidae). All arthropods found in the BPs were adults. We could not detect eggs or early developmental stages, except for the two species with which the plants were inoculated on purpose, T. urticae and A. californicus.

The additional species were found repeatedly only on some species of BPs (Figure 2). Whiteflies of the genus Aleyrodes (more than 5 per plant) were most abundant on Lycopersicon (86\% of infested plants) and Sonchus (43\%), and also on Crepis and Viburnum. Aphids were present on Crepis and Sonchus (less than $20 \%$ of infested plants). Gall midges were found on all species except Lycopersicon and Vitis, mostly on Capsicum, Rosa and Sonchus. Thrips were abundant on Capsicum (more than $40 \%$ of the plants), Sonchus, Vitis and Viburnum.

Encarsia was found mainly on Lycopersicon (more than $40 \%$ of the plants), but also on Crepis, Rosa and Sonchus. The predatory mite Phytoseiulus persimilis was found on $29 \%$ of the plants of Capsicum, and on $14 \%$ of the plants of Eleusine, Viburnum and Vitis. Sonchus was the species of BP that attracted $100 \%$ of the additional present pests. Since this was a non-planned part of the experiment, neither replicates nor statistical analyses were performed here.

The attractiveness exerted by the BPs on the arthropods (pests and natural enemies) differed depending on the plant species. The attraction was strong for A. californicus to Crepis, for gall midges to Capsicum and Rosa, and Encarsia sp. to Lycopersicon. In contrast, attraction was low for $P$. persimilis and gall midges to Eleusine, as well as for Encarsia sp. to Crepis. Finally, three species attracted neither the pests nor the natural enemies: Vitis (gall midges, Encarsia sp.), Capsicum and Eleusine (Encarsia sp.).

On the roses associated to different species of BPs, the spontaneously settled arthropods were not equally distributed. Whiteflies, gall midges and thrips were present only on roses associated to certain species of BPs (Figure 3A, C, D). Aphids were present on roses associated to all species of $\mathrm{BP}$ (Figure $3 \mathrm{~B}$ ). The beneficial organism $P$. persimilis, was not present on the roses. 
The roses associated to Vitis were less infested by other arthropods than those associated to the other species of BPs. Only aphids colonized them.
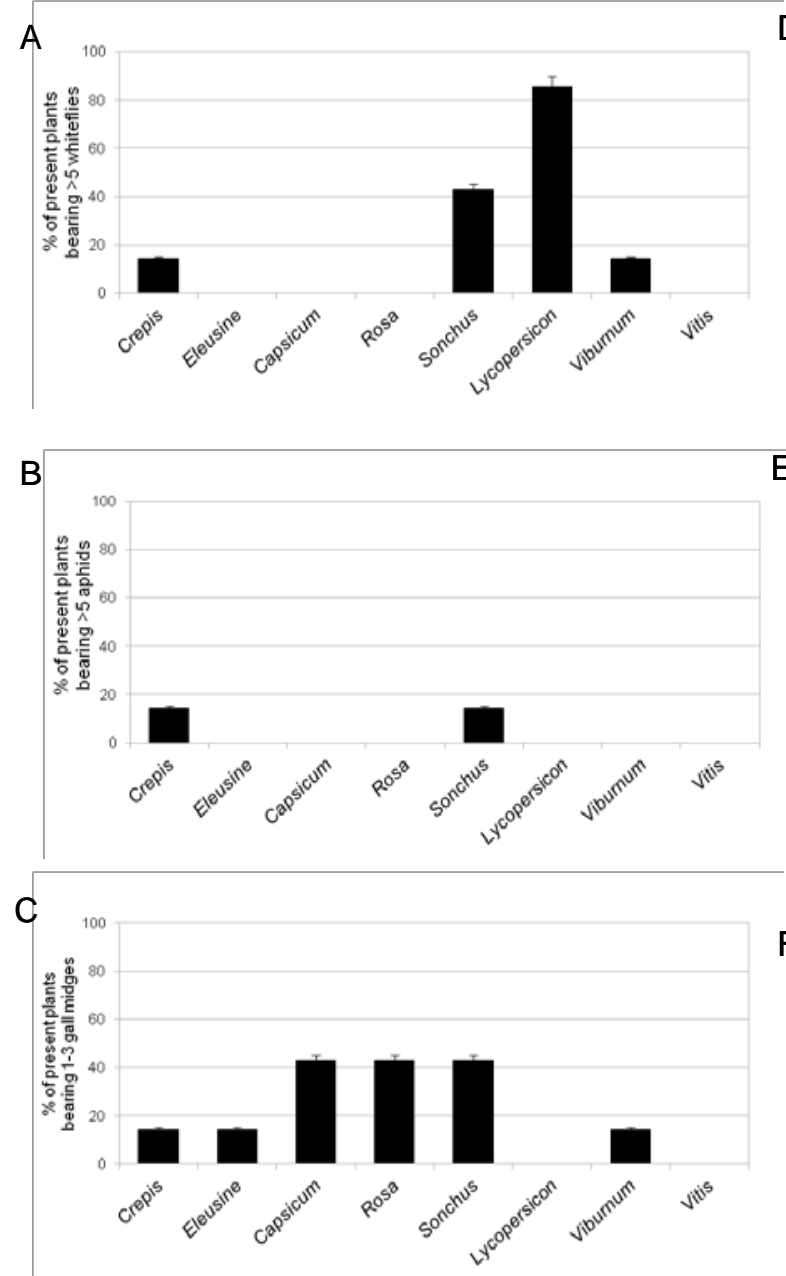

Figure 2. Percentage of banker plants bearing more than 5 individuals of pest organisms not intentionally introduced into the experiment after three months: (A) $>5$ individuals of whiteflies, (B) $>5$ individuals of aphids, (C) 1-3 individuals of gall midges Feltiella, (D) 1-3 individuals of thrips, (E) 1-3 individuals of the parasitic wasp Encarsia sp., and (F) 1-3 individuals of the predatory mite Phytoseiulus persimilis.

\section{Discussion.}

The eight species of BPs attracted different arthropods. This agrees with other studies where the efficiency to maintain a reproducing population of mites differed significantly with the BP species and its characteristics (Parolin et al. 2013). Only some
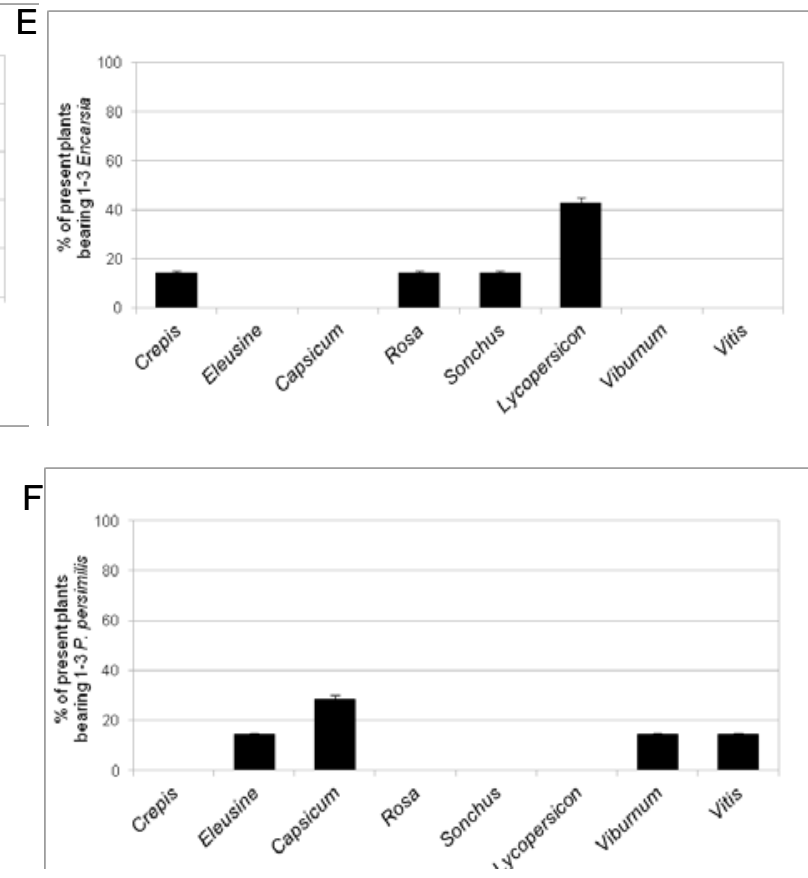

species of plants had a positive influence on the presence of the desired predatory mites. The same could be observed in the present study, where some species of potential BP attracted more pests than

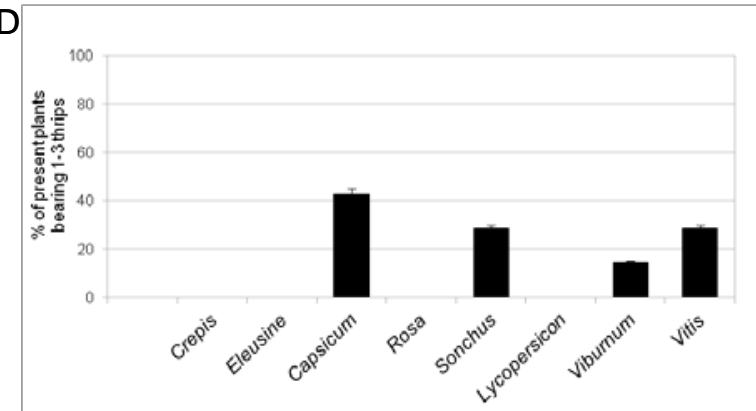


Although it seems almost impossible to avoid the entrance and presence of arthropods in open greenhouses (Poncet et al. 2008), our study shows that with a high diversity of (plant) species present in the greenhouse, the pest abundance may be contained. We assume that the origin of the spontaneous arthropods was from adjacent greenhouses and crop plants, since other greenhouses are located around the greenhouse where the current experiment was conducted and where some of the mentioned arthropods are present. However, because the arthropod pests did not reproduce, they did not represent a danger for the crop plants. The duration of the experiment (3 months) was long enough for several reproductive cycles of all arthropods found on the plants, but still their number did not increase significantly over time.

The presence of the predatory mite $P$. persimilis on some plants may be the result of preestablished populations which were present when the plants were delivered from producers. Their presence was observed on plants of Viburnum that were received from the nursery Les Chênes Verts Orléans, France. The plant has domatia where the mites can hide (Parolin et al., 2011; Parolin et al. 2012c).

Despite the spontaneous appearance and presence of several pest species, the results of our study show that the size of the population of the arthropod pests was rather moderate even after 3 months in the greenhouse.

Overall this study reveals how a diversified crop system can contribute to a partial ecological equilibrium even in open greenhouse conditions, and that secondary plants, in particular BPs, may play an important role in this context (Frank, 2010; Huang et al., 2011; Parolin et al., 2012 a, b). To understand the reasons for this
A

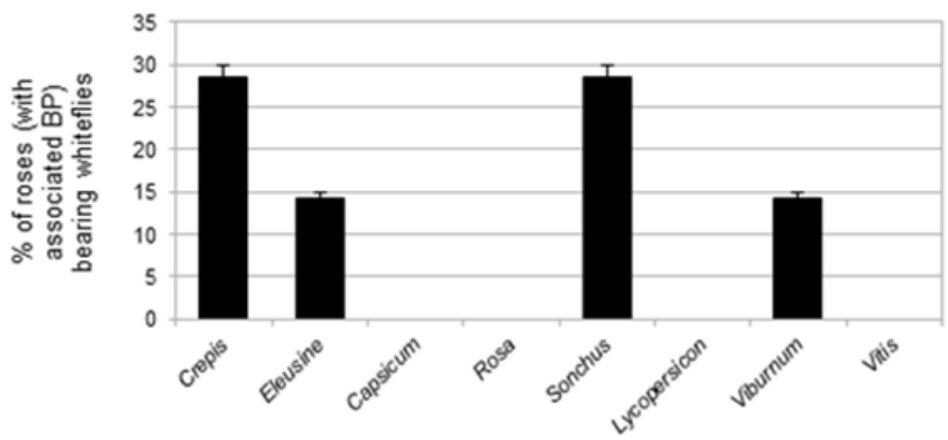

B

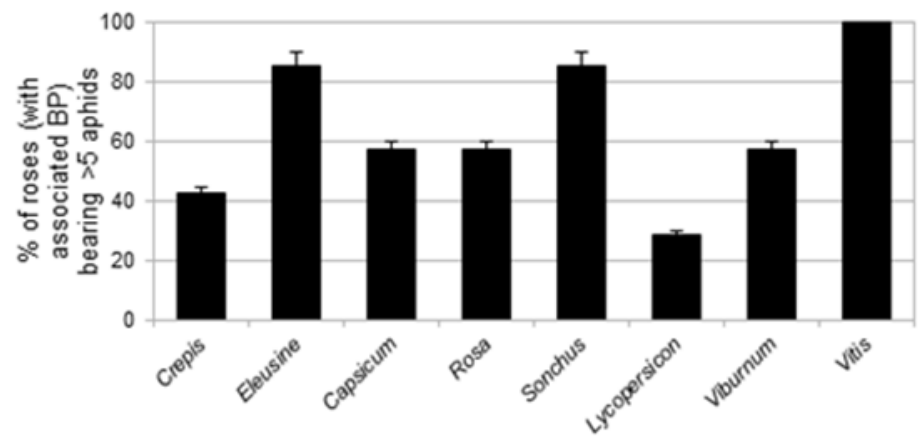

C

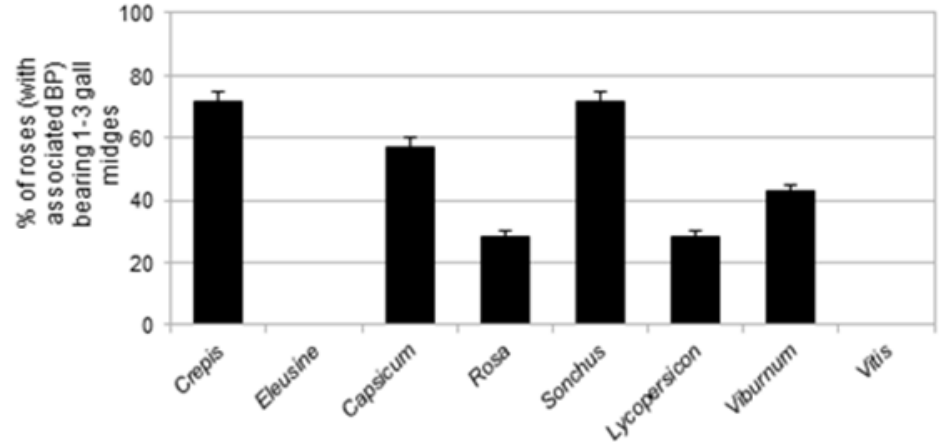

D

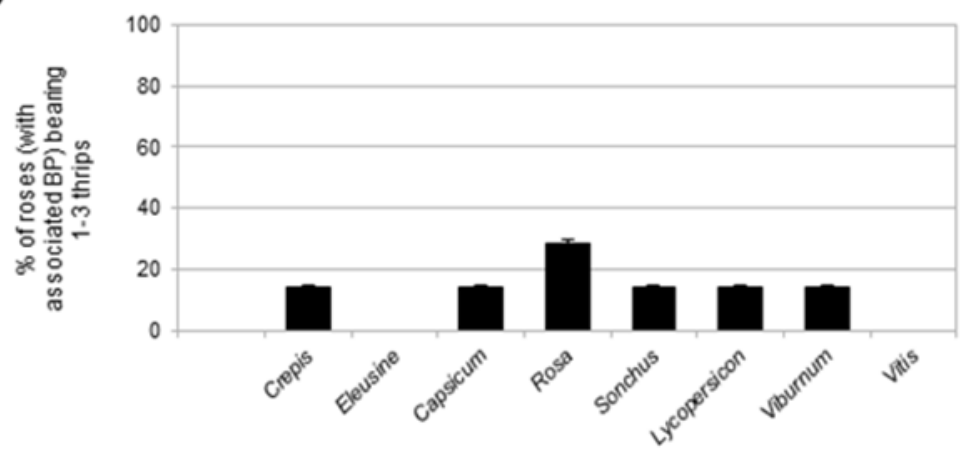

Figure 3. Percentage of roses associated to different species of banker plants (BP) bearing other pest organisms not intentionally introduced into the experiment after three months: (A) whiteflies, (B) aphids, (C) gall midges Feltiella, (D) thrips. 
equilibrium it is important to continue analyzing the biotic interactions between species (plants, pests, and natural enemies) in order to improve the efficiency of biological control with the aid of secondary plants (Pratt \& Croft, 2000; Skirvin \& Fenlon, 2001; Van Driesche et al., 2008). Based on our findings, we support the idea of diversification of a greenhouse crop system. The occurrence of polyculture in our experiment enables to avoid the lack of ecological features of monocultural cropping systems (Scott Brown et al., 1999, Prasifka et al., 2005). Rose plants in a neighboring greenhouse were completely infested by spider mites and other pest arthropods, which was not the case in our experiment under the same environmental conditions. Efficient biotic regulation (Altieri, 1992) occurs in diversified crops, where the herbivore population is more efficiently suppressed, the enemy population is enhanced, and the impact on crop damage are significantly lower than on crops with none or fewer associated plant species (Letourneau et al., 2011). Structural complexity of the plants is known to grant a larger range of microhabitat niches, and to enable the persistence of higher natural enemy species diversity (Tylianakis \& Romo, 2010; Parolin et al. 2012c), even if other experiments contradict this hypothesis (Warfe \& Barmuta, 2004; Aquilino et al., 2005). In case of heterogeneity of the prey resource or of the habitat structure, the effect of enemy diversity on prey suppression may increase (Wellnitz \& Poff, 2001; Schmitz, 2007; Tylianakis et al., 2008).

\section{Acknowledgments.}

This work was supported by a Post-Doc grant from the Department Plant Health and Environment of INRA, for which we are grateful.

\section{References.}

Altieri M. 1992. Agroecological foundations of alternative agriculture in California. Agriculture Ecosystems and Environment 39:23-53.

Aquilino K. M., Cardinale B. J. \& Ives A. R. 2005 Reciprocal effects of host plant and natural enemy diversity on herbivore suppression: An empirical study of a model tritrophic system. Ecology Letters 108:275282.

Casey C. A. \& Parrella M. P. 2005. Evaluation of a mechanical dispenser and interplant bridges on the dispersal and efficacy of the predator, Phytoseiulus persimilis (Acari : Phytoseiidae) in greenhouse cut roses. Biological Control 32:130-136.

Casey C., Newman J., Robb K., Tjosvold S.A., MacDonald J.D. \& Parrella M.P. 2007. IPM program successful in California greenhouse cut roses. California Agriculture 61:71-78.

Frank S.D. 2010. Biological control of arthropod pests using banker plant systems: Past progress and future directions. Biological Control 52:8-16.

Huang N., Enkegaard A., Osborne L.S., Ramakers P.M.J., Messelink G.J., Pijnakker J. \& Murphy G. 2011. The banker plant method in biological control. Critical Reviews in Plant Sciences 30:259-278.

Johnston M. 1993. The searching behaviour of the predatory midge larva, Feltiella acurisuga Vallot in response to the density and distribution of its prey, Tetranychus urticae. Unpubl.Master Thesis Simon Fraser University, Canada.

Letourneau D.K., Armbrecht I., Salguero Rivera B., Montoya LermaJ., Jiménez Carmona E., Daza M.C., Escobar S., Galindo V., Gutiérrez C., Duque López S., López Mejía J., Acosta Rangel A.M., Herrera Rangel J., RiveraL., Saavedra C.A., Torres A.M. \& Reyes Trujillo A. 2011. Does plant diversity benefit agroecosystems? A synthetic review. Ecological Applications 21:9-21.

Maelzer D. 1977. Biology and main causes of changes in numbers of rose aphid, Macrosiphum rosae L., on cultivated roses in South Australia. Australian Journal of Zoology 25:269-284.

Parolin P., Bresch C., Muller M.M., Errard A., \& Poncet C. 2011. Distribution of acarodomatia and predatory mites on Viburnum tinus. Journal of Mediterranean Ecology 11:41-48.

Parolin P, Bresch C., Bout A., Ruiz G., Poncet C., \& Desneux N. 2012a. Testing banker plants for predator installation. Acta Horticulturae 927:211-217.

Parolin P., Bresch C., Brun R., Bout A., Boll R., Desneux N. \& Poncet C. 2012b. Secondary plants used in biological control: a review. International Journal of Pest Management 58(2):91-100.

Parolin P., Bresch C., Poncet C. \& Desneux N. 2012c. Functional characteristics of secondary plants for increased pest management. International Journal of Pest Management 58(4):369-377.

Parolin P., Bresch C., Ruiz G., Desneux N. \& Poncet C. 2013. Testing banker plants for biological control of mites on roses. Phytoparasitica. DOI: 10.1007/s12600012-0285-6.

Paynter Q. \& Bellgrad S. 2011. Understanding dispersal rates of invading weed biocontrol agents. Journal of Applied Ecology 48:407-414.

Poncet C., Vaglio J., Bout A., Mailleret L. \& Boll R. 2008. Spatio-temporal distribution of plant bioaggressors in greenhouses: Towards a better knowledge of disease and pest dynamics.ISHS International Workshop on Greenhouse Environmental Control and Crop Production in Semi-Arid Regions. Tucson, USA. Acta Horticulturae 797:229-234.

Prasifka J.R., Hellmich R.L., Dively G.P. \& Lewis L.C. 2005. Assessing the Effects of Pest Management on Nontarget Arthropods: The Influence of Plot Size and Isolation. Environmental Entomology 34(5):1181-1192.

Pratt P. \& Croft B. 2000. Banker plant: evaluation of release strategies for predatory mites. Journal of Environmental Horticulture18:211-217.

Rhainds M. \& Shipp L. 2004. Dispersal of adult western flower thrips (Thysanoptera: Thripidae) in greenhouse crops. The Canadian Entomologist136:241-254.

Schmitz O.J. 2007. Predator diversity and trophic interactions. Ecology 88:2415-2426.

Scott Brown A.S., Simmonds M.S.J. \& Blaney, W.M. 1999: Influence of species of host plants on the predation of thrips by Neoseiulus cucumeris, Iphiseius degenerans and Orius laevigatus. Entomologia Experimentalis et Applicata 92: 283-288. 
Skirvin D. \& Fenlon J. 2001. Plant species modifies the functional response of Phytoseiulus persimilis (Acari: Phytoseiidae) to Tetranychus urticae (Acari: Tetranychidae): implication for biological control. Bulletin of Entomological Research 91:61-67.

Stacey DL 1977. 'Banker' plant production of Encarsia formosa Gahan and its use in the control of glasshouse whitefly on tomatoes. Plant Pathology 26:63-6.

Tylianakis J.M. \& Romo C.M. 2010. Natural enemy diversity and biological control: Making sense of the context-dependency. Basic and Applied Ecology 11:657-668.

Tylianakis J. M., RandT. A., Kahmen A., Klein A. M., Buchmann N., Perner J. 2008. Resource heterogeneity moderates the biodiversity-function relationship in real world ecosystems. PLoS Biology 6:947-956.

Van Driesche R.G., Lyon S., Sanderson J.P., Bennett K.C., Stanek E.J. \& Zhang R.T. 2008. Greenhouse Trials of

${ }^{1}$ INRA, UR 880, F-06903 Sophia Antipolis, France
Aphidiuscolemani (Hymenoptera: Braconidae) Banker Plants For Control of Aphids (Hemiptera: Aphididae) In Greenhouse Spring Floral Crops. Florida Entomologist 91:583-591.

Van Lenteren J.C. \& Hulspas-Jordaan P.M. 1983. Biological control of the greenhouse whitefly Trialeurodes vaporariorum (Westwood) at low greenhouse temperatures: a summary. University of Leiden.

Warfe D. M.,\&Barmuta L. A. 2004. Habitat structural complexity mediates the foraging success of multiple predator species. Oecologia 141:171-178.

Wellnitz T. \& Poff N. 2001. Functional redundancy in heterogeneous environments: implications for conservation. Ecology Letters 4:177-179.

Zehnder G., Gurr G. M., Kuehne S., Wade M. R., Wratten S. D. \& Wyss E. 2007. Arthropod pest management in organic crops. Annual Review of Entomology 52:57-80. 